\title{
Complications of diazoxide treatment in persistent neonatal hyperinsulinism
}

\author{
Y K ABU-OSBA, ${ }^{*} \mathrm{~K}$ B MANASRA,$\dagger$ AND P M MATHEW $\dagger$ \\ ${ }^{*}$ Neonatology/Perinatology Section, King Faisal Specialist Hospital and Research Centre, Riyadh, and \\ tDepartment of Paediatrics, Dhahran Health Centre, ARAMCO, Dhahran, Saudi Arabia
}

SUMMARY Seven infants with persistent neonatal hyperinsulinism were treated in Dhahran Health Centre from 1983 to 1986. The insulin:glucose ratio (serum insulin concentration pmol/l) divided by the blood glucose concentration (mmol/l) ranged from 12 to 636, mean (SD) 177 (201). To control hypoglycaemia, diazoxide $(12-24 \mathrm{mg} / \mathrm{kg} /$ day) was given in a continuous intravenous glucose infusion (12-22 $\mathrm{mg} / \mathrm{kg} / \mathrm{min})$ on 11 separate occasions, four infants twice each and three infants once each. An increase of more than one standard deviation in the heart and respiratory rates, together with other symptoms of heart failure, was considered to be evidence of diazoxide toxicity. Cardiorespiratory failure (toxicity) occurred on eight of the 11 occasions $\mathbf{( 7 3 \% )}$ in seven infants. The average daily fluid intake, weight change, respiratory rate and heart rate before treatment were similar whether or not the infant developed toxicity. A diazoxide toxicity index was obtained by multiplying the dose of diazoxide by the insulin:glucose ratio to relate the diazoxide dose to the severity of the disease. In all instances when the toxicity index was more than 1533 (mean (SD) 3732 (2741)) cardiac toxicity developed. In contrast, infants with a toxicity index of less than 675 (mean (SD) 364 (270)), had no symptoms of toxicity. Symptoms were significantly related to the severity of the disease and the diazoxide dose. It is possible to use the toxicity index to predict the risk of toxicity and to calculate a safe dose of diazoxide in infants with persistent neonatal hyperinsulinism.

Persistent neonatal hyperinsulinism is an uncommon disease characterised by hyperplasia of the $\beta$ cells of the pancreas and persistent inappropriate hyperinsulinaemia and hypoglycaemia. ${ }^{1-3}$ Medical treatment of the associated hypoglycaemia is often difficult despite adequate glucose intake and various drug regimens. Diazoxide, a non-diuretic benzothiadizine, has been used in various doses to achieve euglycaemia. ${ }^{3-5}$ Cardiorespiratory failure has been reported, ${ }^{4-6}$ the cause of which is not clear. We report the complications encountered during diazoxide treatment of seven patients with persistent neonatal hyperinsulinism, and discuss the possible causes for cardiorespiratory failure.

\section{Subjects and methods}

During the years 1983-6 seven infants with persistent neonatal hyperinsulinism were admitted to Dhahran Health Centre in the eastern province of Saudi Arabia, where a high incidence of persistent neo- natal hyperinsulinism (one in 2675 live births) has been reported. ${ }^{7}$

There were three boys and four girls, all born at full term. Birth weights ranged from 3640 to $5020 \mathrm{~g}$ (mean (SD) 4054 (448) g); three were large for gestational age. All parents had consanguinous marriages. Details of the clinical characteristics and presentation have been reported elsewhere. ${ }^{7}$ All seven infants had persistent refractory hypoglycaemia (blood glucose concentration $<2.22 \mathrm{mmol} / \mathrm{l}$ with a glucose intake of $>12 \mathrm{mg} / \mathrm{kg} /$ minute) in association with inappropriate hyperinsulinaemia.

Histopathological studies of the pancreas from all seven patients showed generalised hyperplasia of the $\beta$ cells. Medical management was attempted for two to four weeks before pancreatectomy; this included intravenous glucose infusion from 12 to 22 $\mathrm{mg} / \mathrm{kg} / \mathrm{min}$, glucagon, corticosteroids, adrenaline, epinephrine, chlorothiazide, and diazoxide in various doses and combinations. Full details of the medical management has been reported elsewhere. ${ }^{7}$ 
Diazoxide was given in 11 instances (four infants twice each, and three infants once each) in doses ranging from 12 to $24 \mathrm{mg} / \mathrm{kg} /$ day for varying periods. All seven patients were given a trial of diazoxide before pancreatectomy was carried out. In addition, cases 1,2 , and 3 were given diazoxide after partial pancreatectomy for hypoglycaemia, and case 4 received diazoxide in two different trials before pancreatectomy.

To determine the side effects of diazoxide, documentation of signs and symptoms of heart failure were looked for retrospectively. The average respiratory rate and heart rate before and during treatment with diazoxide were calculated from the two hourly nursing observations. Weight was measured daily, and average weight gain $(\mathrm{g} / \mathrm{kg} / \mathrm{day})$ was calculated daily; the average daily fluid intake during treatment was also calculated. Chest radiographs were evaluated and the cardiothoracic ratio was determined. The electrocardiograms and echocardiograms were reviewed by an independent cardiologist.

The degree of inappropriate hyperinsulinaemia was expressed by the ratio of serum insulin $(\mathrm{pmol} / \mathrm{l})$ to blood glucose concentration $(\mathrm{mmol} / \mathrm{l})$. To compare the effects of diazoxide in relation to the severity of the disease as judged by the insulin: glucose ratio, a toxicity index was calculated by multiplying the insulin:glucose ratio by the diazoxide dose $(\mathrm{mg} / \mathrm{kg} /$ day $)$.

Diazoxide toxicity was diagnosed if the following criteria were present: the heart rate and respiratory rate had increased by more than one standard deviation from the mean rate before treatment, and the infant developed cardiomegaly, heart mumur, or hepatomegaly. Student's $t$ test and Fisher's exact test were used for assessing the significance of differences as appropriate.

\section{Results}

Three boys and four girls met the criteria of persistent neonatal hyperinsulinism during the study period (table 1). In three of 11 instances of diazoxide treatment, no significant changes occurred in the cardiorespiratory state, but in the remaining eight signs of cardiorespiratory failure developed (table 2).

The serum insulin concentrations ranged between 29 and $843 \mathrm{pmol} / \mathrm{l}$, and the insulin:glucose ratio ranged between 12 and 636 (table 1). Blood glucose tended to be lower and serum insulin higher in the infants who developed symptoms of toxicity compared with those who did not $(\mathrm{p}<0.1$ and $\mathrm{p}<0.025$, respectively). Symptoms of cardiorespiratory failure occurred whenever the insulin:glucose ratio rose above 63 , and in none of the infants with a glucose insulin/ratio of less than 33. Even case 6 is excluded (his insulin:glucose ratio was more than two standard deviations above the mean) there was a significant difference in insulin:glucose ratio between those who developed complications and those who did not $(p<0.02)$.

The toxicity index range between 191 and 9543 . It was significantly higher in infants who were toxic than in those who were not $(p<0 \cdot 011)$. All patients with toxicity indexes of 675 and below had no symptoms of toxicity. In contrast, all patients with

Table 1 Insulin and glucose concentrations and diazoxide toxicity index

\begin{tabular}{|c|c|c|c|c|c|}
\hline Case No & Insulin (pmol/l) & Glucose (mmolll) & $\begin{array}{l}\text { Insulin:glucose } \\
\text { ratio }\end{array}$ & $\begin{array}{l}\text { Diazoxide } \\
\text { (mg/kg/day) }\end{array}$ & $\begin{array}{l}\text { Toxicity } \\
\text { index }\end{array}$ \\
\hline \multicolumn{6}{|l|}{ Toxic infants: } \\
\hline 1 & 307 & 1.056 & 291 & 18 & 5238 \\
\hline $1^{*}$ & 121 & 1.056 & 115 & 18 & 2071 \\
\hline 2 & 400 & $2 \cdot 333$ & 171 & 12 & 2057 \\
\hline 3 & 107 & $1 \cdot 315$ & 83 & 24 & 1995 \\
\hline 4 & 89 & 1.417 & 64 & 24 & 1533 \\
\hline 5 & 111 & 0.972 & 107 & 23 & 2455 \\
\hline 6 & 843 & $1 \cdot 361$ & 636 & 15 & 9543 \\
\hline 7 & 386 & $1 \cdot 167$ & 331 & 15 & 4959 \\
\hline Mean (SD) & $296(257)$ & $1.334(0.434)$ & $225(193)$ & $18 \cdot 6(4 \cdot 6)$ & $3732(2741)$ \\
\hline \multicolumn{6}{|c|}{ Infants who were not toxic: } \\
\hline $2^{*}$ & 29 & $1 \cdot 889$ & 15 & 15 & 227 \\
\hline $3^{*}$ & 50 & 1.556 & 32 & 21 & 675 \\
\hline 4 & 29 & $2 \cdot 389$ & 12 & 16 & 191 \\
\hline Mean (SD) & $36(12)$ & $1.944(0.419)$ & $20(11)$ & $17(3 \cdot 2)$ & $364(270)$ \\
\hline p Valuet & $0 \cdot 025$ & $0 \cdot 123$ & $0 \cdot 02$ & $0 \cdot 623$ & $0 \cdot 011$ \\
\hline
\end{tabular}

*After partial pancreatectomy; tcomparing the means of the two groups. 
Table 2 Clinical changes during diazoxide treatment

\begin{tabular}{|c|c|c|c|c|c|c|c|c|}
\hline \multirow[t]{2}{*}{ Case No } & \multirow{2}{*}{$\begin{array}{l}\text { Weight gain } \\
\text { (g/kg/day) }\end{array}$} & \multirow{2}{*}{$\begin{array}{l}\text { Intake } \\
\text { (ml/kg/day) }\end{array}$} & \multicolumn{2}{|c|}{ Pulse/minute } & \multicolumn{2}{|c|}{ Respiration/minute } & \multirow{2}{*}{$\begin{array}{l}\text { Heart } \\
\text { murmur }\end{array}$} & \multirow{2}{*}{$\begin{array}{l}\text { Period } \\
\text { (days) }\end{array}$} \\
\hline & & & $\begin{array}{l}\text { Before } \\
\text { treatment }\end{array}$ & $\begin{array}{l}\text { During } \\
\text { treatment }\end{array}$ & $\begin{array}{l}\text { Before } \\
\text { treatment }\end{array}$ & $\begin{array}{l}\text { During } \\
\text { treatment }\end{array}$ & & \\
\hline \multicolumn{9}{|l|}{ Toxic infants: } \\
\hline 1 & $-7 \cdot 0$ & 144 & 130 & 180 & 57 & 75 & $3 / 6$ & 4 \\
\hline $1^{*}$ & $21 \cdot 8$ & 150 & 140 & 190 & 44 & 66 & $3 / 6$ & 4 \\
\hline 3 & $17 \cdot 6$ & 215 & 134 & 170 & 48 & 54 & $2 / 6$ & 16 \\
\hline 4 & $6 \cdot 0$ & 168 & 150 & 168 & 47 & 56 & $2 / 6$ & 2 \\
\hline 5 & $25 \cdot 4$ & 220 & 146 & 160 & 49 & 63 & $3 / 6$ & 2 \\
\hline 6 & $3 \cdot 0$ & 193 & 120 & 155 & 47 & 66 & $2 / 6$ & 9 \\
\hline 7 & $10 \cdot 1$ & 172 & 155 & 165 & 46 & 64 & $3 / 6$ & 7 \\
\hline Mean (SD) & $10 \cdot 0(10.9)$ & $177(29 \cdot 5)$ & $141(12 \cdot 4)$ & $168(11 \cdot 8)$ & $49(4 \cdot 7)$ & $66(9 \cdot 5)$ & . & $5.9(4 \cdot 8)$ \\
\hline \multicolumn{9}{|c|}{ Infants who were not toxic: } \\
\hline $3^{*}$ & $2 \cdot 0$ & 131 & 126 & 130 & 35 & 39 & None & 16 \\
\hline 4 & $7 \cdot 56$ & 164 & 144 & 140 & 51 & 50 & None & 7 \\
\hline Mean (SD) & $6.0(3.4)$ & $163(31 \cdot 5)$ & $137(9.9)$ & $137(5 \cdot 8)$ & $44(8 \cdot 1)$ & $43(6 \cdot 1)$ & & $10(5 \cdot 2)$ \\
\hline p Valuet & 0.374 & 0.559 & $0 \cdot 626$ & $0 \cdot 001$ & $0 \cdot 377$ & $0 \cdot 005$ & & $0 \cdot 317$ \\
\hline
\end{tabular}

*After partial pancreatectomy; tcomparing the means of the two groups.

indexes of 1533 and above developed symptoms of toxicity. When we compared infants with indexes of more than 1500 with those who had indexes of less than 1500 the difference was significant $(p=0.006)$. The diazoxide dose was similar in both groups, $(\mathrm{p}=0.62)$.

In all the infants with symptoms of toxicity, cardiomegaly and heart murmurs (grade 2/6-3/6) developed (table 2). There was no significant difference in the heart rate before diazoxide treatment in the two groups. In comparison, the heart rate differed significantly in the two groups during treatment $(p<0 \cdot 001)$. The heart rate was similar before and during diazoxide treatment in infants without complications, though it differed significantly in infants with complications $(p<0.01)$.

The respiratory rate was similar in both groups before diazoxide treatment and did not change during treatment in the group who did not become toxic. There was a significant increase in the respiratory rate during diazoxide treatment in the group who became toxic $(\mathrm{p}<0 \cdot 01)$. Two infants, (cases 1 and 5) required mechanical ventilation with oxygen requirements of up to $100 \%$.

Echocardiograms were done in patients 1,5 , and 7 and did not show any structural lesion. Cardiorespiratory symptoms resolved in all infants within 2-4 days after diazoxide was discontinued. Digoxin was not used. Chlorothiazide was given in conjunction with diazoxide, and frusemide was given as needed.
The average fluid intake and weight gain of the two groups of infants during treatment did not differ.

Temperatures between $36.5^{\circ} \mathrm{C}$ and $38.5^{\circ} \mathrm{C}$ were noticed in four infants who became toxic. A picture mimicking sepsis was also seen, and antibiotics were given to five infants. In none of these infants was any micro-organisms grown from blood, urine, or cerebrospinal fluid. Symptoms of central nervous system impairment including fussiness, irritability, jitterness, and diaphoresis were seen in five infants without hypoglycaemia. Three infants had seizure activity during diazoxide treatment that required anticonvulsant treatment. Blood glucose, calcium, magnesium, and electrolyte concentrations were normal when these episodes occurred.

\section{Discussion}

Hypoglycaemia in infants with persistent neonatal hyperinsulinism often requires various management regimens despite a high glucose infusion rate. Diazoxide in various doses had been used in combination with other drugs to control hypoglycaemia. ${ }^{3-5}$ We have presented seven patients with persistent neonatal hyperinsulinism who received diazoxide in varying doses to control the blood glucose, and congestive heart failure occurred in all seven patients during eight treatment periods. The cause of the heart failure in similar infants is not clear from the few reported cases. ${ }^{4-6}$ 
Fluid intake was within the normal range, and there was no significant difference in the fluid intake between those who became toxic and those who did not. The weight gain during diazoxide treatment was within the normal range, and did not differ between the groups. All patients were on appropriate doses of chlorothiazide during diazoxide treatment. Our findings confirm those of McGraw and Price, who found no appreciable weight gain in a patient with nesidioblastosis who developed heart failure while receiving diazoxide treatment. ${ }^{4}$ Heart failure resolved gradually in all patients within two to four days of discontinuing diazoxide. In view of these findings it is unlikely that fluid overload was the cause for the heart failure in these infants. A direct toxic effect of diazoxide on the myocardium seems to be a more probable explanation.

Poor myocardial function in hyperinsulinaemic states such as in infants of diabetic mothers has been well described. ${ }^{8}$ None of our patients had structural heart disease or signs of heart failure before diazoxide treatment was started, and the heart failure that developed during diazoxide treatment resolved in all patients after the diazoxide was stopped. None of our patients received digoxin, and the rationale was that these patients have a hyperinsulinaemic state, and the myocardial state and function are most likely to be similar to those of infants of diabetic mothers. ${ }^{89}$

High doses of diazoxide (up to $20-25 \mathrm{mg} / \mathrm{kg} /$ day) have been recommended in an attempt to avoid operation, and heart failure had been attributed to the use of these high doses. ${ }^{3-5} 10$ In our study there was no significant difference in diazoxide dose in infants with complications and those without. Our patients who developed heart failure, however, had high blood insulin and low blood glucose concentrations compared with those who did not develop complications. The insulin:glucose ratio was higher in those with, compared with those without, heart failure. These findings support the hypothesis that the more severe the disease state-even in the same patient - the more susceptible that patients is to the toxic effects of diazoxide. The diazoxide toxicity index was used in this study as a predictor of susceptibility to cardiorespiratory failure by combining the effect of diazoxide dose and the severity of the hyperinsulinaemic state. Our results show that toxicity symptoms occurred in a patient who received diazoxide in a dose as low as $12 \mathrm{mg} / \mathrm{kg} /$ day and did not occur in a patient who received a dose as high as $21 \mathrm{mg} / \mathrm{kg} /$ day.

All infants with an insulin:glucose ratio of more than 64 (more severe disease) and a toxicity index of more than 1533 developed symptoms of toxicity, and all infants with an insulin:glucose ratio of less than 32 (less severe disease) and a toxicity index of less than 675 did not. It seems that an insulin:glucose ratio above 48 and a toxicity index above 1104 (mid points between the lowest values of infants who became toxic and the highest values for infants who did not are values above which symptoms of toxicity are likely to occur. If diazoxide has to be used, a probable safe dose can be calculated if the insulin: glucose ratio is known, by dividing 1104 by the insulin glucose:ratio, with a maximum dose of 25 $\mathrm{mg} / \mathrm{kg} / \mathrm{day}$.

Some other serious complications were observed in conjunction with diazoxide. Convulsions and other central nervous system symptoms that were noticed in our patients cannot be attributed solely to diazoxide, as hypoglycaemia is known to cause these symptoms, and ataxia has been reported by McGraw and Price in a patient with nesidioblastosis on diazoxide treatment. ${ }^{4} \mathrm{~A}$ clinical picture mimicking sepsis that required treatment with antibiotics is another problem that may mislead the physician to institute unnecessary investigations and treatment. As in some previous reports, ${ }^{11}{ }^{12}$ all our patients except one required $95 \%$ to total pancreatectomy to control the blood glucose.

In summary, serious complications including cardiorespiratory failure were encountered during diazoxide treatment of seven infants with persistent neonatal hyperinsulinism. Cardiorespiratory failure was closely related to both the diazoxide dose and the severity of the disease. Further studies including measurements of the indices of left ventricular function will help to clarify further the cardiotoxic effect in such patients. By using the toxicity index it may be possible to predict which patients are likely to develop cardiorespiratory failure during diazoxide treatment.

We thank Professor D Milner and Dr N Sakati for reviewing the manuscript. We are grateful to the nursing staff of the neonatal intensive care unit, Dhahran Health Centre, and we thank Ms J Nerit for secretarial help.

\footnotetext{
References

1 Yakovac WC, Baker L, Hummeler K. Beta cell nesidioblastosis in idiopathic hypoglycemia of infancy, J Pediatr 1971;79:226-31.

2 Heitz PU, Kloppel G, Hacki WH, Polak JM, Pearse AGE. Morphologic and quantitative analysis of seven cases based on specific immunostaining and electron microscopy. Diabetes 1977;26:632-42.

3 Aynsley-Green A, Polak JM, Bloom SR, et al. Nesidioblastosis of the pancreas: definition of the syndrome and the management of the severe neonatal hyperinsulinaemic hypoglycaemia. Arch Dis Child 1981;56:496-508.

${ }^{4}$ McGraw ME, Price DA. Complications of diazoxide in the treatment of nesidioblastosis. Arch Dis Child 1985;60:62-4.

5 Gillies DR. Complications of diazoxide in the treatment of nesidioblastosis. Arch Dis Child 1985;60:500-1.

6 Abu-Osba YK, Young M. Cardiorespiratory failure secondary
} 
to diazoxide treatment in nesidioblastosis: report of a case. Annals of Saudi Medicine 1988;8:498-500.

7 Mathew PM, Young JM, Abu-Osba YK, et al. Persistent neonatal hyperinsulinism. Clin Pediatr 1988:27:148-51.

${ }^{8}$ Breitweser JA, Meyer RA. Sperling MA, Tsang RC, Kaplan S. Cardiac septal hypertrophy in hyperinsulinemic infants. $J$ Pediatr 1980;96:535-9.

${ }^{9}$ Gutgesell HP, Speer ME, Rosenberg HS. Characterization of cardiomyopathy in infants of diabetic mothers. Circulation 1980:61:441-50.

10 Sovik O, Vidnes J, Falkner S, et al. Persistent neonatal hypoglycemia, Acta Pathologica et Microbiologica Scandinavica, Section A, Pathology 1975;83:155-66.
1 Garces LY, Drash A, Kenny FM. Islet cell tumor in the neonate. Studies in carbohydrate metabolism and therapeutic repsonse. Pediatrics 1968:41:789-96.

12 Salinas ED Jr. Mangurten HH, Roberts SS, Simon WH. Cornblath M. Functioning islet cell adenoma in the newborn. Report of a case with failure of diazoxide. Pediatrics 1968:41: 646-53.

Correspondence to Dr YK Abu-Osba, Neonatology/Perinatology Section, Pediatric Department, King Faisal Specialist Hospital and Research Centre, PO Box 3354, Riyadh 11211, Saudi Arabia.

Accepted 31 May 1989 